\title{
Antidepressant use and work-related injuries
}

\author{
A. Kouvonen ${ }^{1,2,3 *}$, J. Vahtera ${ }^{4,5}$, J. Pentti ${ }^{4}$, M. J. Korhonen ${ }^{6}$, T. Oksanen ${ }^{4}$, P. Salo $^{4}$, M. Virtanen ${ }^{4}$ and \\ M. Kivimäki ${ }^{4,7,8}$ \\ ${ }^{1}$ Department of Social Research, University of Helsinki, Helsinki, Finland \\ ${ }^{2}$ Faculty in Wroclaw, University of Social Sciences and Humanities, Wroclaw, Poland \\ ${ }^{3}$ UKCRC Centre of Excellence for Public Health (Northern Ireland), Queen's University Belfast, Belfast, UK \\ ${ }^{4}$ Finnish Institute of Occupational Health, Turku and Helsinki, Finland \\ ${ }^{5}$ Department of Public Health, University of Turku, and Turku University Hospital, Turku, Finland \\ ${ }^{6}$ Department of Pharmacology, Drug Development and Therapeutics, University of Turku, Turku, Finland \\ ${ }^{7}$ Department of Epidemiology and Public Health, University College London, London, UK \\ ${ }^{8}$ Department of Public Health, University of Helsinki, Helsinki, Finland
}

Background. Adverse effects of antidepressants are most common at the beginning of the treatment, but possible also later. We examined the association between antidepressant use and work-related injuries taking into account the duration of antidepressant use.

Method. Antidepressant use and work-related injuries between 2000 and 2011 were measured among 66238 employees (mean age 43.8 years, $80 \%$ female) using linkage to national records (the Finnish Public Sector study). We analysed data using time-dependent modelling with individuals as their own controls (self-controlled case-series design).

Results. In 2238 individuals who had used antidepressants and had a work-related injury during a mean follow-up of 7.8 years, no increase in the risk of injury was observed in the beginning of antidepressant treatment. However, an increased injury risk was seen after 3 months of treatment (rate ratio, compared with no recent antidepressant use, $1.27,95 \%$ confidence interval 1.10-1.48). This was also the case among those who had used only selective serotonin reuptake inhibitors $(n=714$; rate ratio $1.41,95 \%$ confidence interval 1.08-1.83).

Conclusions. Antidepressant use was not associated with an increased risk of work-related injury at the beginning of treatment. Post-hoc analyses of antidepressant trials are needed to determine whether long-term use of antidepressants increases the risk of work-related injury.

Received 21 May 2015; Revised 23 November 2015; Accepted 28 November 2015; First published online 25 January 2016

Key words: Antidepressants, commuting injuries, occupational injuries, public sector, workplace, work-related injuries.

\section{Introduction}

Antidepressants are currently among the most prescribed drugs worldwide (Reid \& Barbui, 2010). In the USA in 2007-2010, for example, $8 \%$ of adults at 18 to 44 years of age and $14 \%$ of those at 45 to 64 years of age had used antidepressants in the past 30 days (National Center for Health Statistics, 2013). However, antidepressants may affect cognition and, recently, it has been suggested that the use of antidepressants might cause unwanted side-effects increasing the risk of work-related injuries (Palmer et al. 2014).

The evidence on the link between antidepressant use and work-related injuries is still scarce and inconsistent. In a recent case-control study, the likelihood of consultation for workplace injury was increased among individuals using antidepressants (Palmer

\footnotetext{
* Address for correspondence: A. Kouvonen, Department of Social Research, PO Box 18, 00014 University of Helsinki, Finland.

(Email: anne.kouvonen@helsinki.fi)
}

et al. 2014). A prospective study found an association between antidepressant use and risk of unintentional injury (Tiesman et al. 2006), and in a cross-sectional study psychotropic drug use was associated with occupational injuries (Bhattacherjee et al. 2003). In contrast, another cross-sectional study found no association between psychotropic medication use and work accidents (Wadsworth et al. 2005), and two case-control studies found little evidence of increased risk of occupational injury in those using any psychotropic drugs (Gilmore et al. 1996; Pickett et al. 1996).

Importantly, duration of antidepressant use immediately preceding work-related injury was not assessed in these studies. This is a major limitation because many adverse effects of antidepressants are most common at the beginning of the treatment, but usually wear off over a couple of weeks or lead to revising or discontinuing medication (Royal College of Psychiatrists, 2015). To address this limitation, we conducted a large-scale study to examine the association between antidepressant use and work-related injuries

This is an Open Access article, distributed under the terms of the Creative Commons Attribution licence (http://creativecommons.org/licenses/by/4.0/), which permits unrestricted re-use, distribution, and reproduction in any medium, provided the original work is properly cited. 
using two separate designs following the analytical approach of Coupland et al. $(2011 a, b)$. In the main analysis we applied time-dependent modelling using individuals as their own controls [self-controlled caseseries (SCCS) method]. This method allowed us to determine whether those who had used antidepressants and had had an injury were likely to have used antidepressants specifically at the time of the injury and what was their treatment duration; or whether they had stopped the use shortly before the injury. In sensitivity analyses, a regular prospective cohort design that included also non-exposed and non-injured participants was used.

\section{Method}

\section{Study population and design}

This study is a part of the Finnish Public Sector study, which is a cohort study of employees working in 10 towns and six hospital districts (Kivimäki et al. 2010). The eligible population comprised 99699 employees in service and targeted by questionnaire surveys in 2000-2002, 2004 and/or 2008. The Finnish Public Sector study cohort includes more than a thousand occupational titles. The most common occupational titles are childminder, kindergarten assistant, practical nurse, teacher, nurse, secretary and cleaner (Salo et al. 2012). Participants were linked to employers' records and national health registers using unique national personal identification numbers. According to the Finnish law, written consent is not required for survey and register-based research, as long as participation is voluntary; and the participants were informed about the study aims and the possible record linkages. The completion of the questionnaire acts as informed consent. The study was approved by the Ethics Committee of the Hospital District of Helsinki and Uusimaa.

In all, 78317 (79\%) eligible employees responded at least once. The first response was included for those who responded to more than one questionnaire. The prospective cohort, which was used in a sensitivity analysis, included 66238 participants and did not substantially differ from the eligible population in terms of mean age ( 43.8 years in the sample, 42.8 years in the eligible population), the proportion of women $(80 \%$ v. $77 \%$ ) or the proportion of manual workers (16\% v. $20 \%)$. The date of the survey response was defined as the date of cohort entry for the prospective cohort.

Our analytical sample for the main analyses included 2238 participants with at least one antidepressant purchase and work-related injury during the study period. The date of the beginning of the preexposure time (i.e. 30 days preceding the first initiation of antidepressants), or survey response date if on treatment, was defined as the index date.

\section{Assessment of antidepressant use (exposure)}

We extracted information on all purchases of antidepressants [Anatomical Therapeutic Chemical (ATC) code N06A] from the Finnish Prescription Register. The Finnish Prescription Register is kept by the Social Insurance Institution and includes records of all drug purchases reimbursed to Finnish residents in non-institutional settings. For each dispensed drug, the record includes the dispensing date, the World Health Organization (WHO) ATC code (WHO Collaborating Centre for Drug Statistics Methodology, 2013), and the quantity purchased as the number of defined daily dose (DDD), a proxy for the number of days treated (WHO Collaborating Centre for Drug Statistics Methodology, 2013). We extracted information on all purchases of antidepressants (ATC code N06A) in our analytic sample, following their index date during follow-up. All purchases between the index date and 31 December 2011 were included. The time intervals between days covered by medication and those not covered were used to determine the exposed and unexposed periods for each participant. For this, we first determined the periods covered by antidepressants. For each period, we used the dispensation date as the start date and projected the end date using the total number of DDDs dispensed, and combined consecutive and overlapping periods of medication to form continuous periods of treatment. A maximum duration for one dispensation was set to 100 days corresponding to the maximum of days' supply that can be reimbursed per purchase. To take into account the possibility that the actual dose was half of the DDD, we prospectively added to the end date the number of DDDs of the prescription using 50 DDDs as a maximum to fill the gap between prescriptions. This is a validated method to calculate the number of days a patient had a medication available during the follow-up (Lau et al. 1997).

\section{Assessment of work-related injury (outcome)}

We obtained records on work-related injuries from the nationwide register kept by the Federation of Accident Insurance Institutions. In Finland, all work-related injuries are compensated through a statutory employer insurance system. Compensation for occupational injuries takes priority over other forms of statutory compensation and pensions. Commuting injuries are treated similarly as occupational injuries. We measured the occurrence of the first recorded injury between the index date and 31 December 2011. In the Finnish Public Sector study, dislocations, sprains and 
strains ( $41 \%$ of all injuries) are the most frequent types of injury, upper extremities (36\%) is the most common injury location; and slipping, tripping, stumbling and falling $(25 \%)$ is the most common events category (Kouvonen et al. 2013).

\section{Covariates}

Since the method used in our main analysis implicitly controls for the effects of all measured and unmeasured fixed confounders, covariates were included only in additional sensitivity analysis in a prospective cohort design. We measured covariates at the cohort entry. Age, sex, job contract type and occupational status (Virtanen et al. 2011) were derived from employers' records. Marital status, health-risk behaviours and health-related variables were obtained from the surveys. We measured smoking, high alcohol consumption (Rimm et al. 1999), insufficient physical activity (Kujala et al. 1998), body mass index, self-rated health (Idler \& Benyamini, 1997), insomnia symptoms (Jenkins et al. 1988), usual sleep duration and psychological distress (Goldberg \& Williams, 1988). Purchases of anxiolytics and sedatives (N05B) and hypnotics (N05C) were included in further sensitivity analysis.

\section{Statistical analysis}

To reduce the limitations of the cohort design approach and to address indication bias, we applied the SCCS method (Whitaker et al. 2006; Coupland et al. 2011a), and investigated the association between antidepressant use and injuries using only data on those antidepressant users who had had a work-related injury during the follow-up. Because this method is a within-individuals comparison, the effects of all measured and unmeasured fixed confounders are implicitly controlled for (Whitaker et al. 2006). This method has previously been used to examine the relationship between antidepressant use and a range of adverse outcomes, including falls, fractures and road traffic accidents in older adults (Coupland et al. 2011a), and the relationships between prescription drugs and the risk of motor vehicle crashes in adults (Gibson et al. 2009). To account for participants stopping and re-starting treatments, antidepressant use was considered as a time-varying exposure that could change in value over the entire follow-up period (Allison, 2010). From the index date, we determined whether the participant was using (exposed to) or not using (unexposed to) antidepressants until the end of follow-up. Since employees cannot experience work-related injury during sick leave or on the periods they are not employed, we excluded these periods from our analysis. This information was extracted from the records kept by the employers (sick leaves) and the Finnish Centre for Pensions (employment contracts). Following the approach applied by Coupland et al. $(2011 a, b)$ we examined the duration of the treatment as a time-varying exposure based on time between initiation and discontinuation of antidepressant treatment, categorized as 1-30 days before the first dispensation (pre-exposure period), 1-30 days' use, 31-90 days' use, 91 or more days of use; and periods of 1-30 days, 31-90 days, $91-180$ days and $>180$ days after stopping treatment. The last category was treated as the unexposed period (the reference category). We used a SAS macro for conditional Poisson regression models (http://statistics.open.ac.uk/sccs) to estimate rate ratios (RRs) and their 95\% confidence intervals (CIs).

To allow for estimation of the absolute risk of injury associated with antidepressant use, we conducted a sensitivity analysis using a regular prospective cohort design, in which all cohort participants were included. We determined the periods of use (exposure) and non-use (non-exposure) of antidepressants for each participant between the cohort entry and the end of follow-up. We estimated the associations between exposure to antidepressants and work-related injuries with time-dependent Cox proportional hazard models, adjusting hazard ratios (HRs) (95\% CIs) for potential confounders measured at the cohort entry. Participants were followed until either the first injury, move abroad, death, or 31 December 2011, whichever came first. For these analyses, we used the SAS program package, version 9.4 (SAS Institute, Inc.; USA).

\section{Ethical statement}

All procedures contributing to this work comply with the ethical standards of the relevant national and institutional committees on human experimentation and with the Helsinki Declaration of 1975, as revised in 2008.

\section{Results}

Sociodemographic characteristics of the included participants at cohort entry, the number of antidepressant treatment days per person-year and the number of injuries per 100 person-years are presented in Table 1 . In the SCCS analysis cohort, the mean follow-up was 7.8 years between 2000 and 2011. In the total prospective cohort, the injury risk was 4.3 per 100 person-years for exposed time and 3.5 per 100 person-years for nonexposed time.

Table 2 summarizes the results from the SCCS analysis examining the association between the duration of antidepressant use and work-related injuries. The 
Table 1. Characteristics of the two cohorts at cohort entry, the Finnish Public Sector Study, 2000-2011

\begin{tabular}{|c|c|c|c|c|c|c|}
\hline \multirow[b]{2}{*}{ Characteristic } & \multicolumn{3}{|c|}{ SCCS cohort ${ }^{\mathrm{a}}$} & \multicolumn{3}{|c|}{ Prospective cohort ${ }^{b}$} \\
\hline & $n(\%)$ & $\begin{array}{l}\text { Days of } \\
\text { antidepressant } \\
\text { use/person-year }\end{array}$ & $\begin{array}{l}n \text { of } \\
\text { injuries/100 } \\
\text { person-years }\end{array}$ & $n(\%)$ & $\begin{array}{l}\text { Days of } \\
\text { antidepressant } \\
\text { use/person-year }\end{array}$ & $\begin{array}{l}n \text { of } \\
\text { injuries/100 } \\
\text { person-years }\end{array}$ \\
\hline \multicolumn{7}{|l|}{ Sex } \\
\hline Women & $1943(87)$ & 150.1 & 15.9 & $53195(80)$ & 21.2 & 3.5 \\
\hline Men & $295(13)$ & 139.7 & 16.6 & $13043(20)$ & 15.2 & 4.1 \\
\hline \multicolumn{7}{|l|}{ Age, years } \\
\hline 18 to 39 & $559(25)$ & 140.2 & 16.7 & $22349(34)$ & 17.0 & 3.2 \\
\hline 40 to 49 & $903(40)$ & 151.8 & 15.5 & $22158(33)$ & 22.2 & 3.7 \\
\hline 50 to 67 & $776(35)$ & 149.8 & 16.1 & $21731(34)$ & 21.6 & 3.9 \\
\hline \multicolumn{7}{|l|}{ Occupational status } \\
\hline Higher non-manual & $476(21)$ & 151.4 & 15.7 & $20544(31)$ & 19.4 & 2.4 \\
\hline Lower non-manual & $1291(58)$ & 149.6 & 16.0 & $34838(53)$ & 20.9 & 3.5 \\
\hline Manual & $471(21)$ & 143.6 & 16.5 & $10856(16)$ & 18.4 & 6.6 \\
\hline \multicolumn{7}{|l|}{ Married or cohabiting } \\
\hline Yes & $1486(66)$ & 146.6 & 15.7 & $50233(76)$ & 18.2 & 3.5 \\
\hline No & $752(34)$ & 154.7 & 16.6 & $16005(24)$ & 26.2 & 4.0 \\
\hline \multicolumn{7}{|l|}{ Type of job contract } \\
\hline Permanent & $1854(83)$ & 151.4 & 16.0 & $53393(81)$ & 20.9 & 3.7 \\
\hline Fixed-term & $384(17)$ & 136.0 & 16.1 & $12845(19)$ & 17.4 & 3.1 \\
\hline \multicolumn{7}{|l|}{ Current smoking } \\
\hline No & $1673(75)$ & 149.1 & 15.9 & $54618(82)$ & 18.8 & 3.4 \\
\hline Yes & $565(25)$ & 149.9 & 16.2 & $11620(18)$ & 26.3 & 4.3 \\
\hline \multicolumn{7}{|l|}{ Heavy drinking } \\
\hline No & $2033(91)$ & 148.4 & 16.0 & $60918(92)$ & 19.8 & 3.6 \\
\hline Yes & $205(9)$ & 152.5 & 16.2 & $5320(8)$ & 23.0 & 3.7 \\
\hline \multicolumn{7}{|c|}{ Insufficient physical activity } \\
\hline No & $1600(71)$ & 146.9 & 15.8 & $49886(75)$ & 18.4 & 3.5 \\
\hline Yes & $638(29)$ & 153.6 & 16.5 & $16352(25)$ & 25.4 & 3.7 \\
\hline \multicolumn{7}{|c|}{ Suboptimal self-rated health } \\
\hline No & $1366(61)$ & 143.5 & 16.0 & $50556(76)$ & 15.3 & 3.3 \\
\hline Yes & $872(39)$ & 157.1 & 16.0 & $15682(24)$ & 37.9 & 4.5 \\
\hline \multicolumn{7}{|l|}{ Insomnia symptoms } \\
\hline No or moderate & $1445(65)$ & 147.7 & 16.1 & $51458(78)$ & 16.1 & 3.5 \\
\hline Severe & 793 (35) & 150.7 & 15.9 & $14780(22)$ & 35.3 & 4.0 \\
\hline \multicolumn{7}{|l|}{ Sleep duration } \\
\hline $6.5 \mathrm{~h}$ or less & $594(27)$ & 140.6 & 16.5 & $14661(22)$ & 21.9 & 4.2 \\
\hline 7 to $8.5 \mathrm{~h}$ & $1548(69)$ & 149.8 & 15.8 & $49316(75)$ & 19.0 & 3.4 \\
\hline $9 \mathrm{~h}$ or more & $96(4)$ & 181.6 & 15.9 & $2261(3)$ & 33.8 & 4.0 \\
\hline \multicolumn{7}{|l|}{ Psychological distress } \\
\hline No & $1335(60)$ & 145.9 & 16.5 & $49907(75)$ & 15.7 & 3.5 \\
\hline Yes & $903(40)$ & 152.8 & 15.4 & $16331(25)$ & 33.9 & 4.0 \\
\hline \multicolumn{7}{|l|}{ Body mass index, $\mathrm{kg} / \mathrm{m}^{2}$} \\
\hline$<18.5$ & $28(1)$ & 141.1 & 16.7 & $816(1)$ & 19.9 & 3.3 \\
\hline 18.5 to 24.9 & $1147(51)$ & 142.4 & 15.5 & $35820(54)$ & 18.0 & 3.2 \\
\hline 25 to 29.9 & $675(30)$ & 150.1 & 16.4 & $21325(32)$ & 21.4 & 4.0 \\
\hline $30+$ & $388(17)$ & 167.9 & 17.0 & $8247(13)$ & 27.8 & 4.6 \\
\hline
\end{tabular}

SCCS, Self-controlled case-series.

${ }^{a}$ SCCS cohort: participants with at least one antidepressant purchase and injury during the follow-up $(n=2238)$.

${ }^{\mathrm{b}}$ Prospective cohort: all participants with data on antidepressants, injuries and covariates $(n=66238)$. 
Table 2. Risk of work-related injury by duration of antidepressant use among participants with at least 1 antidepressant prescription and injury, conditional Poisson regression (self-controlled case-series design, n=2238), the Finnish Public Sector Study, Finland, 2000-2011

\begin{tabular}{|c|c|c|c|}
\hline $\begin{array}{l}\text { Antidepressant } \\
\text { use duration }\end{array}$ & Person-years & $\begin{array}{l}\text { Number } \\
\text { of first } \\
\text { injuries }\end{array}$ & $\begin{array}{l}\text { Rate ratio } \\
(95 \% \mathrm{CI})\end{array}$ \\
\hline $\begin{array}{l}1-30 \text { days } \\
\text { before use }\end{array}$ & 512 & 95 & $1.18(0.94-1.48)$ \\
\hline 1-30 days' use & 585 & 94 & $1.07(0.85-1.34)$ \\
\hline 31-90 days' use & 921 & 153 & $1.14(0.94-1.38)$ \\
\hline $\begin{array}{l}91 \text { or more days' } \\
\text { use }\end{array}$ & 4195 & 718 & $1.27(1.10-1.48)$ \\
\hline $\begin{array}{l}\text { Stopped 1-30 } \\
\text { days }\end{array}$ & 385 & 64 & $1.05(0.80-1.36)$ \\
\hline $\begin{array}{l}\text { Stopped 31-90 } \\
\text { days }\end{array}$ & 577 & 100 & $1.06(0.85-1.31)$ \\
\hline $\begin{array}{l}\text { Stopped } 91-180 \\
\text { days }\end{array}$ & 671 & 119 & $1.06(0.87-1.29)$ \\
\hline $\begin{array}{l}\text { Stopped } 180+ \\
\text { days }\end{array}$ & 6139 & 895 & 1.00 (reference) \\
\hline
\end{tabular}

CI, Confidence interval.

results show that compared with stopping treatment over 6 months ago, only 3 months' or more of exposure to antidepressants was associated with a higher risk of work-related injury ( $R R=1.27,95 \%$ CI $1.10-1.48)$. A similar association was also observed when those who had used other psychotropic drugs than antidepressants during follow-up were excluded from the analysis $(n=1021)(\mathrm{RR}=1.27,95 \%$ CI $1.01-1.61)$ (data not shown).

Table 3 shows the results from the SCCS analysis examining the association between the duration of selective serotonin reuptake inhibitor (SSRI) use and the risk of injury. We excluded those SSRI users who had used other classes of antidepressants during the study period. The results were in line with the results obtained from the analysis including all antidepressant classes: compared with stopping the treatment over 6 months ago, only 3 months' or more of exposure to SSRIs was associated with a higher risk of workrelated injury ( $R R=1.41,95 \%$ CI 1.08-1.83).

Table 4 shows the results of the sensitivity analysis in a regular prospective cohort design. Compared with non-use, antidepressant use was associated with an elevated risk of work-related injury $(\mathrm{HR}=1.22$, 95\% CI 1.14-1.30) and this association attenuated slightly after adjustment for sex, age, marital status, occupational status, type of job contract, health-risk
Table 3. Risk of work-related injury by duration of SSRI use among participants with at least one SSRI prescription and injury, conditional Poisson regression (self-controlled case-series design, $\mathrm{n}=714$ ), the Finnish Public Sector Study, Finland, 2000-2011

\begin{tabular}{|c|c|c|c|}
\hline $\begin{array}{l}\text { SSRI use } \\
\text { duration }\end{array}$ & $\begin{array}{l}\text { Person- } \\
\text { years }\end{array}$ & $\begin{array}{l}\text { Number of } \\
\text { first injuries }\end{array}$ & $\begin{array}{l}\text { Rate ratio } \\
(95 \% \mathrm{CI})\end{array}$ \\
\hline $\begin{array}{l}1-30 \text { days before } \\
\text { use }\end{array}$ & 109 & 23 & $1.28(0.81-2.02)$ \\
\hline 1-30 days' use & 121 & 16 & $0.85(0.50-1.45)$ \\
\hline 31-90 days' use & 234 & 36 & $1.03(0.71-1.50)$ \\
\hline $\begin{array}{l}91 \text { or more days' } \\
\text { use }\end{array}$ & 1205 & 230 & $1.41(1.08-1.83)$ \\
\hline $\begin{array}{l}\text { Stopped 1-30 } \\
\text { days }\end{array}$ & 93 & 17 & $1.16(0.70-1.92)$ \\
\hline $\begin{array}{l}\text { Stopped 31-90 } \\
\text { days }\end{array}$ & 150 & 33 & $1.38(0.95-2.00)$ \\
\hline $\begin{array}{l}\text { Stopped } 91-180 \\
\text { days }\end{array}$ & 185 & 39 & $1.29(0.91-1.82)$ \\
\hline $\begin{array}{l}\text { Stopped 180+ } \\
\text { days }\end{array}$ & 2334 & 320 & 1.00 (reference) \\
\hline
\end{tabular}

SSRI, Selective serotonin reuptake inhibitor; CI, confidence interval.

a Participants with purchases of other classes of antidepressants during the study period were excluded.

behaviours, body mass index, self-rated health, insomnia symptoms, sleep duration and psychological distress $(\mathrm{HR}=1.14,95 \% \mathrm{CI} 1.07-1.22)$.

\section{Discussion}

In this study, no increase in workplace injury risk was observed at the beginning of antidepressant treatment and thus our initial hypothesis was refuted. However, over 3 months' antidepressant use was associated with a $27 \%$ elevated risk of work-related injury. Similar results were obtained when the analysis was restricted to SSRI users. The novelty of our study lies in the timedependent design which took into account the duration of treatment, and the use of the SCCS method. An advantage of this method is that a person acts as his/her own control so that confounding factors that do not vary with time, such as genetics and socioeconomic background, cannot distort the findings.

The similarities and discrepancies between the results from the SCCS analyses and those from the sensitivity analyses based on the prospective cohort data deserve to be discussed. We consider SCCS analyses as the primary analysis and those based on the cohort data as secondary analysis because the first is less vulnerable to confounding that artificially inflates or attenuates associations. Our cohort analysis adds to 
Table 4. Adjusted hazard ratios for work-related injury by antidepressant use in the total cohort ( $\mathrm{n}=66238)$, the Finnish Public Sector Study, Finland, 2000-2011

\begin{tabular}{|c|c|c|c|c|c|}
\hline Antidepressant use & Person-years & $\begin{array}{l}\text { Number of } \\
\text { first injuries }\end{array}$ & $\begin{array}{l}\text { Model } 1^{\mathrm{a}} \text { : hazard } \\
\text { ratio }(95 \% \mathrm{CI})\end{array}$ & $\begin{array}{l}\text { Model } 2^{\mathrm{b}} \text { : hazard } \\
\text { ratio }(95 \% \mathrm{CI})\end{array}$ & $\begin{array}{l}\text { Model } 3^{c}: \text { hazard } \\
\text { ratio }(95 \% \mathrm{CI})\end{array}$ \\
\hline Any antidepressant use & 22981 & 977 & $1.22(1.14-1.30)$ & $1.21(1.13-1.29)$ & $1.14(1.07-1.22)$ \\
\hline No antidepressant use & 394780 & 13960 & 1.00 (reference) & 1.00 (reference) & 1.00 (reference) \\
\hline
\end{tabular}

CI, Confidence interval.

${ }^{\text {a }}$ Model 1: unadjusted.

${ }^{\mathrm{b}}$ Model 2: adjusted for sex, age, marital status and occupational status.

${ }^{c}$ Model 3: additionally adjusted for type of job contract, health-risk behaviours (smoking, heavy drinking, insufficient physical activity), body mass index, self-rated health, insomnia symptoms, sleep duration and psychological distress (General Health Questionnaire 12).

the main analysis by allowing the use of a much larger and less selected population than the SCCS analysis. The cohort design also enabled us to estimate the absolute risk of injury associated with antidepressant use, in addition to relative risk. Furthermore, because the prospective cohort approach is commonly used in previous studies, its use allows for comparability of findings.

The HR of 1.14 (95\% CI 1.07-1.22) from the total cohort for the comparison between any use and no use of antidepressants is close to the HR $(1.15,95 \%$ CI $1.02-$ 1.29) obtained from the SCCS analysis when comparing any use (merging periods 1-30 days, 31-90 days and 91 or more days of use) and no use of antidepressants (merging the periods 30 days prior to antidepressant use, 1-30 days, 31-90 days, $91-180$ days and $>180$ days after stopping treatment). The finding that the HR from the SCCS design is slightly higher than the HR based on the total cohort suggests that the elevated HR in the total cohort cannot be explained by unmeasured confounding by invariant intrinsic factors.

The basic assumption of the SCCS method is that the occurrence of an outcome event does not affect the probability of subsequent exposure (Whitaker et al. 2006); indeed, in a previous study the occurrence of occupational injury was linked to an increased likelihood of out-patient treatment for depression (Asfaw \& Souza, 2012). However, as our SCCS analysis design was extended to the pre-exposure time, we were able to distinguish the pre-exposure period from the reference time, thus minimizing any underestimation of the strength of the association.

\section{Possible mechanisms}

Both causal and non-causal mechanisms may explain the unexpected relationship between long-term antidepressant use and increased risk of work-related injury. First, a long-term causal effect is possible because most antidepressants are prescribed by starting at a low dose and, if needed, titrating the dose higher over the course of weeks to months. As such, if a pharmacological effect is the mechanism that increases injury risk the effect may not occur until higher doses are reached. This is biologically plausible. Antidepressant use has been associated with increased risk of falls and fractures (Rizzoli et al. 2012). In a recent study, SSRIs were shown to increase fracture risk among middle-aged women without psychiatric disorders (Sheu et al. 2015). In principle, the use of antidepressants that act on the serotonin system could reduce bone mineral density (BMD) and bone loss, and thus increase fracture risk (Rizzoli et al. 2012; Vestergaard et al. 2013). With SSRIs, for example, the increase in risk has been shown to reach a peak within 8 months' use (Rizzoli et al. 2012). In patients suffering from bone loss the consequence of the injury may be more severe leading to sickness absence and thus becoming recorded. However, most of the previous evidence on antidepressants, BMD, bone loss and fracture risk still relates to older adults.

Second, the possibility that the increased injury risk after 3 months' antidepressant use may be an artefact cannot be excluded in non-randomized studies, such as our investigation. Thus, a possible explanation for our results and previously observed associations is indication bias, that is, the condition for which the drug was prescribed rather than the drug itself increasing the risk (Coupland et al. 2011a). Certain depressive symptoms such as difficulties in concentration, fatigue and insomnia can lead to an increased risk of injury. Indeed, depression has been associated with workrelated injuries (Tiesman et al. 2006; Franche et al. 2009; Palmer et al. 2014), decreased BMD and increased fracture risk (Cizza et al. 2010). Furthermore, antidepressants are prescribed for various conditions, 
although depression is the most common indication particularly for SSRI use. A recent UK study showed that in $87 \%$ of patients prescribed an SSRI the indication was depression or mixed depression and anxiety, and in another 9\% it was anxiety disorder (Johnson et al. 2014). Other classes of antidepressants than SSRI, such as tricyclic antidepressants, are prescribed also for indications other than depression (Beck et al. 2005), and symptoms of these diseases may increase the injury risk (Vingilis \& Wilk, 2012). Moreover, antidepressant use may be a marker of other pre-existing conditions, such as musculoskeletal disorders, heart disease or diabetes, which themselves can increase the injury risk (Kubo et al. 2014).

To determine whether the observed increased risk is caused by antidepressants rather than just being an uninformative marker of other factors, it would be important that new post-hoc analyses of antidepressant trials are performed. Increased injury rates after longterm use ( $>3$ months) of antidepressants in the treatment group compared with the control group would convincingly demonstrate an adverse off-target effect of antidepressants which should be taken into account in clinical practice.

\section{Strengths and limitations}

The main strengths of our study are the prospective use of high-resolution medication data, a record-based measurement of injury in a large cohort, as well as the use of study design which took the duration of antidepressant use into account. The use of comprehensive and reliable register data reduces the risk of misclassification bias. Prescription data were based on a clinical assessment by a physician and cover virtually all dispensed out-patient antidepressant prescriptions. We were able to take into account changes in a person's exposure status and in sensitivity analysis we excluded those who had used other types of psychotropic drugs during the follow-up. We were able to control for such time-dependent biases as immortal time bias by removing periods not at risk from the follow-up, e.g. those due to sickness absence. SCCS implicitly controls for all measured and unmeasured time-invariant confounders thereby largely removing residual confounding and helping to address indication bias (Whitaker et al. 2006).

At least six limitations warrant discussion. First, we only had information that the medication had been dispensed from a pharmacy. It is possible that sometimes medication is purchased but not subsequently taken as prescribed (Modén et al. 2012). Second, the possibility of confounding by indication cannot be avoided in any observational study (Salas et al. 1999). Third, as antidepressant prescribing and the presence and severity of depression change over time and are highly correlated, the analyses cannot separate their effects on injury that in this study was observed only for over 3 months' use of antidepressants. However, it is notable that we did not find any associations between shorter durations of antidepressant treatment and workrelated injury. It seems unlikely that indication or severity biases could have masked the true effect of antidepressant use on the workplace injury risk at the beginning of the treatment. On the contrary, these biases would have rather led to an overestimation of the risk.

Fourth, given that the risk of depression following work-related injury may persist longer than 30 days (Kim, 2013), it is possible that our pre-exposure window of 30 days is too narrow. However, the same preexposure window has been used in previous studies (Coupland et al. 2011b).

Fifth, in our analysis, we removed the periods of time when employees were on sick leave or not employed. If the most severely depressed employees were most likely to be on sick leave after diagnosis when starting their treatment it is possible that this leads to an underestimation of the association during the first 3 months of treatment and when the more severely depressed employees start to return to work, the injury rate increases. However, this confounding by severity of depression and underestimation of risk in the first 3 months is an unlikely explanation for the observations in the present study. In the SCCS analysis cohort, $13.5 \%$ of all person-years in the first month of antidepressant treatment were attributable to sick leaves and therefore excluded from the analysis; the corresponding proportions were $8.1 \%$ in the period more than 90 days of treatment (when the more severely depressed employees presumably start to return to work) and $4.8 \%$ in the reference period $>180$ days after stopping the treatment (see online Supplementary Table S1). Finally, even though controlling for fixed factors, SCCS analyses are still susceptible to confounding from time-varying factors.

\section{Conclusions}

The original hypothesis that adverse effects of antidepressants on work-related injury risk, if any, are seen at the beginning of the treatment when adverse side-effects are most common was not supported. However, we found that more than 3 months of antidepressant use was associated with a slightly increased risk of work-related injury. Further studies, preferably as part of randomized controlled trials, are needed to determine whether the excess risk is due to adverse drug effects. 


\section{Supplementary material}

For supplementary material accompanying this paper visit http://dx.doi.org/10.1017/S0033291715002925

\section{Acknowledgements}

The Finnish Public Sector Study was supported by the Academy of Finland (grants 264944 and 267727) and the participating organizations. A.K. was supported by the Medical Research Council (MRC) (grant MR/ K023241/1) and the Economic and Social Research Council (ESRC) (grant ES/L007509/1). M.K. was supported by the MRC (K013351), the National Heart, Lung and Blood Institute (HL36310), the National Institute of Aging (AG034454), the Academy of Finland and an ESRC professorial fellowship. M.V. was supported by the Academy of Finland (grants 258598, 265174). M.J.K. was supported by the Academy of Finland (grant 138255).

\section{Declaration of Interest}

None.

\section{References}

Allison P (2010). Survival Analysis Using SAS: A Practical Guide. SAS Institute: Cary, NC.

Asfaw A, Souza K (2012). Incidence and cost of depression after occupational injury. Journal of Occupational and Environmental Medicine 54, 1086-1091.

Beck CA, Patten SB, Williams JVA, Wang JL, Currie SR, Maxwell CJ, El-Guebaly N (2005). Antidepressant utilization in Canada. Social Psychiatry and Psychiatric Epidemiology 40, 799-807.

Bhattacherjee A, Chau N, Sierra CO, Legras B, Benamghar L, Michaely J-P, Ghosh AK, Guillemin F, Ravaud J-F, Mur J-M (2003). Relationships of job and some individual characteristics to occupational injuries in employed people: a community-based study. Journal of Occupational Health 45, 382-391.

Cizza G, Primma S, Coyle M, Gourgiotis L, Csako G (2010). Depression and osteoporosis: a research synthesis with meta-analysis. Hormone and Metabolic Research 42, 467-482.

Coupland C, Dhiman P, Barton G, Morriss R, Arthur A, Sach T, Hippisley-Cox J (2011a). A study of the safety and harms of antidepressant drugs for older people: a cohort study using a large primary care database. Health Technology Assessment 15, 1-202, iii-iv.

Coupland C, Dhiman P, Morriss R, Arthur A (2011b). Antidepressant use and risk of adverse outcomes in older people: population based cohort study. BMJ 343, d4551.

Franche R-L, Carnide N, Hogg-Johnson S, Côté P, Breslin FC, Bültmann U, Severin CN, Krause N (2009). Course, diagnosis, and treatment of depressive symptomatology in workers following a workplace injury: a prospective cohort study. Canadian Journal of Psychiatry 54, 534-546.
Gibson JE, Hubbard RB, Smith CJP, Tata LJ, Britton JR, Fogarty AW (2009). Use of self-controlled analytical techniques to assess the association between use of prescription medications and the risk of motor vehicle crashes. American Journal of Epidemiology 169, 761-768.

Gilmore T, Alexander B, Mueller B, Rivara F (1996). Occupational injuries and medication use. American Journal of Industrial Medicine 30, 234-239.

Goldberg D, Williams P (1988). A User's Guide to the General Health Questionnaire. NFER-Nelson Publishing Co.: Windsor.

Idler EL, Benyamini Y (1997). Self-rated health and mortality: a review of twenty-seven community studies. Journal of Health and Social Behavior 38, 21-37.

Jenkins CD, Stanton BA, Niemcryk SJ, Rose RM (1988). A scale for the estimation of sleep problems in clinical research. Journal of Clinical Epidemiology 41, 313-321.

Johnson CF, Dougall NJ, Williams B, MacGillivray Sa, Buchanan AI, Hassett RD (2014). Patient factors associated with SSRI dose for depression treatment in general practice: a primary care cross sectional study. BMC Family Practice 15, 210.

Kim J (2013). Depression as a psychosocial consequence of occupational injury in the US working population: findings from the medical expenditure panel survey. BMC Public Health 13, 303.

Kivimäki M, Hamer M, Batty GD, Geddes JR, Tabak AG, Pentti J, Virtanen M, Vahtera J (2010). Antidepressant medication use, weight gain, and risk of type 2 diabetes: a population-based study. Diabetes Care 33, 2611-2616.

Kouvonen A, Kivimäki M, Oksanen T, Pentti J, De Vogli R, Virtanen M, Vahtera J (2013). Obesity and occupational injury: a prospective cohort study of 69515 public sector employees. PLOS ONE 8, e77178.

Kubo J, Goldstein BA, Cantley LF, Tessier-Sherman B, Galusha D, Slade MD, Chu IM, Cullen MR (2014). Contribution of health status and prevalent chronic disease to individual risk for workplace injury in the manufacturing environment. Occupational and Environmental Medicine 71, 159-166.

Kujala UM, Kaprio J, Sarna S, Koskenvuo M (1998). Relationship of leisure-time physical activity and mortality: the Finnish twin cohort. JAMA 279, 440-444.

Lau HS, de Boer A, Beuning KS, Porsius A (1997). Validation of pharmacy records in drug exposure assessment. Journal of Clinical Epidemiology 50, 619-625.

Modén B, Ohlsson H, Merlo J, Rosvall M (2012). Psychotropic drugs and accidents in Scania, Sweden. European Journal of Public Health 22, 726-732.

National Center for Health Statistics (2013). Health, United States, 2012: With Special Feature on Emergency Care. US Department of Health and Human Services, National Center for Health Statistics: Hyattsville, MD.

Palmer KT, D'Angelo S, Harris EC, Linaker C, Coggon D (2014). The role of mental health problems and common psychotropic drug treatments in accidental injury at work: a case-control study. Occupational and Environmental Medicine 71, 308-312.

Pickett W, Chipman ML, Brison RJ, Holness DL (1996). Medications as risk factors for farm injury. Accident Analysis and Prevention 28, 453-462. 
Reid S, Barbui C (2010). Long term treatment of depression with selective serotonin reuptake inhibitors and newer antidepressants. BMJ 340, 752-756.

Rimm EB, Williams P, Fosher K, Criqui M, Stampfer MJ (1999). Moderate alcohol intake and lower risk of coronary heart disease: meta-analysis of effects on lipids and haemostatic factors. BMJ (Clinical Research ed.) 319, 15231528.

Rizzoli R, Cooper C, Reginster JY, Abrahamsen B, Adachi $J D$, Brandi ML, Bruyère $O$, Compston J, Ducy $P$, Ferrari $S$, Harvey NC, Kanis JA, Karsenty G, Laslop A, Rabenda V, Vestergaard P (2012). Antidepressant medications and osteoporosis. Bone 51, 606-613.

Royal College of Psychiatrists (2015). Antidepressants (http:// www.rcpsych.ac.uk/healthadvice/treatmentswellbeing/ antidepressants.aspx). Accessed December 2015.

Salas M, Hofman A, Strieker BHC (1999). Confounding by indication: an example of variation in the use of epidemiologic terminology. American Journal of Epidemiology 149, 981-983.

Salo P, Ala-Mursula L, Rod NH, Tucker P, Pentti J, Kivimäki M, Vahtera J (2012). Work time control and sleep disturbances : prospective cohort study of Finnish public sector employees. Sleep 37, 1217-1225.

Sheu Y, Lanteigne A, Stürmer T, Pate V, Azrael D, Miller M (2015). SSRI use and risk of fractures among perimenopausal women without mental disorders. Injury Prevention 21, 397-403.
Tiesman HM, Peek-Asa C, Whitten P, Sprince NL, Stromquist A, Zwerling C (2006). Depressive symptoms as a risk factor for unintentional injury: a cohort study in a rural county. Injury Prevention 12, 172-177.

Vestergaard P, Prieto-Alhambra D, Javaid K, Cooper C (2013). Fractures in users of antidepressants and anxiolytics and sedatives: effects of age and dose. Osteoporosis International 24, 671-680.

Vingilis E, Wilk P (2012). Medical conditions, medication use, and their relationship with subsequent motor vehicle injuries: examination of the Canadian National Population Health Survey. Traffic Injury Prevention 13, 327-336.

Virtanen M, Kawachi I, Oksanen T, Salo P, Tuisku K, Pulkki-Råback L, Pentti J, Elovainio M, Vahtera J, Kivimäki M (2011). Socio-economic differences in longterm psychiatric work disability: prospective cohort study of onset, recovery and recurrence. Occupational and Environmental Medicine 68, 791-798.

Wadsworth EJK, Moss SC, Simpson SA, Smith AP (2005). Psychotropic medication use and accidents, injuries and cognitive failures. Human Psychopharmacology 20, 391-400.

Whitaker HJ, Farrington CP, Spiessens B, Musonda P (2006). Tutorial in biostatistics: the self-controlled case series method. Statistics in Medicine 25, 1768-1797.

WHO Collaborating Centre for Drug Statistics Methodology (2013). Guidelines for ATC Classification and DDD Assignment 2014. WHO Collaborating Centre for Drug Statistics Methodology: Oslo. 